\section{Research Motivation and Goals}

$>$ In attempting to understand the challenges faced by Northern Ontario with regards to locally produced food, this research focuses on inventorying the existing production and distribution services available to farmers in Northern Ontario.

$>$ This research attempts to link not only producers and distributors but also various communities through a networked approach.
Identified Barrier: Distance to Farm Services

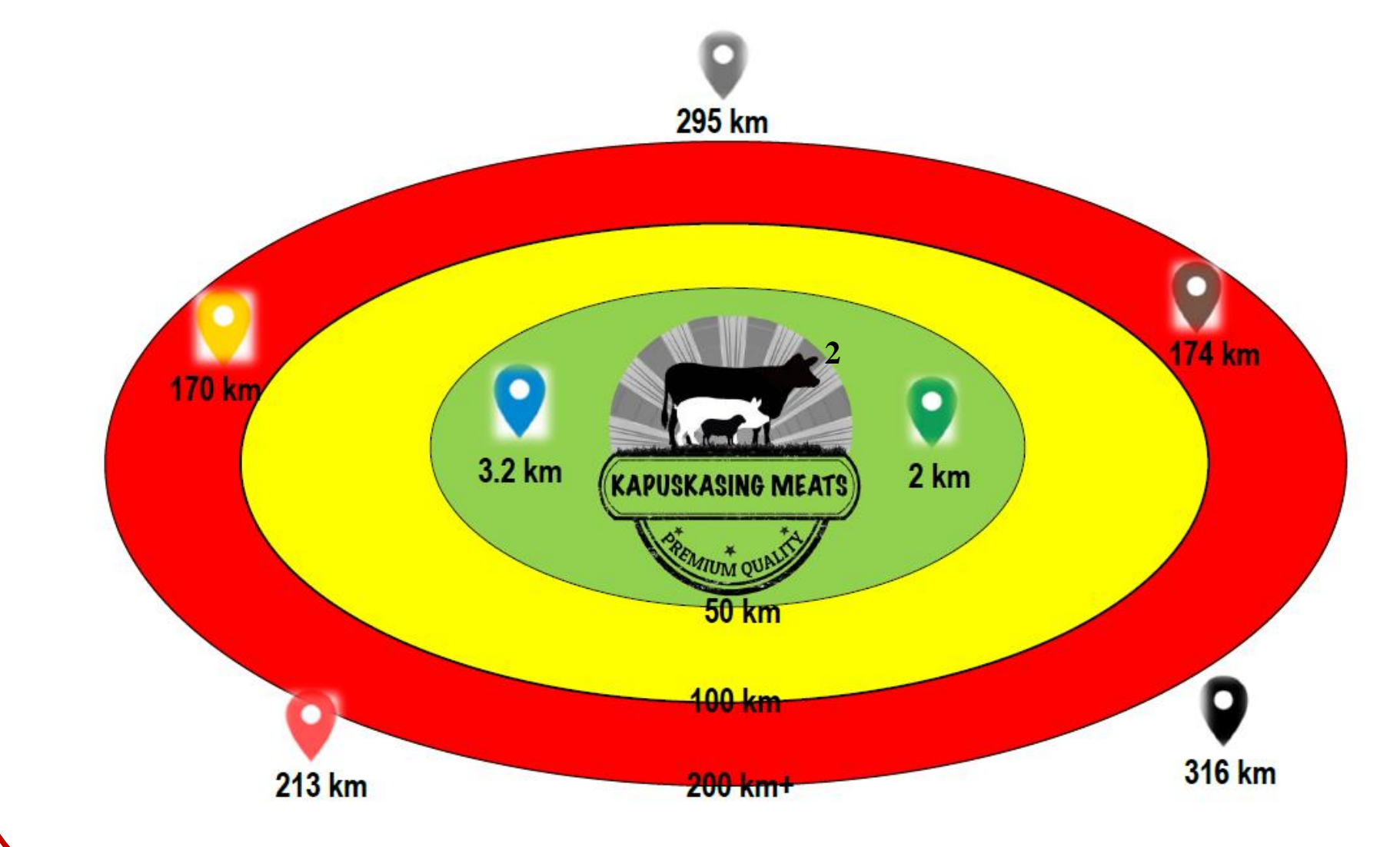

This diagram depicts the distances to farm services for a producer located in Kapuskasing. What is notable is the distance to the nearest abattoir, farm equipment dealer and certified crop advisor.

Farm Services
Abattoir
- Veterinarian
Farmer's Market
- Farm Equipment Sales/Services
Feed \& Seed
- Certified Crop Advisor
- Livestock Transport \& Sales

Special thanks to:
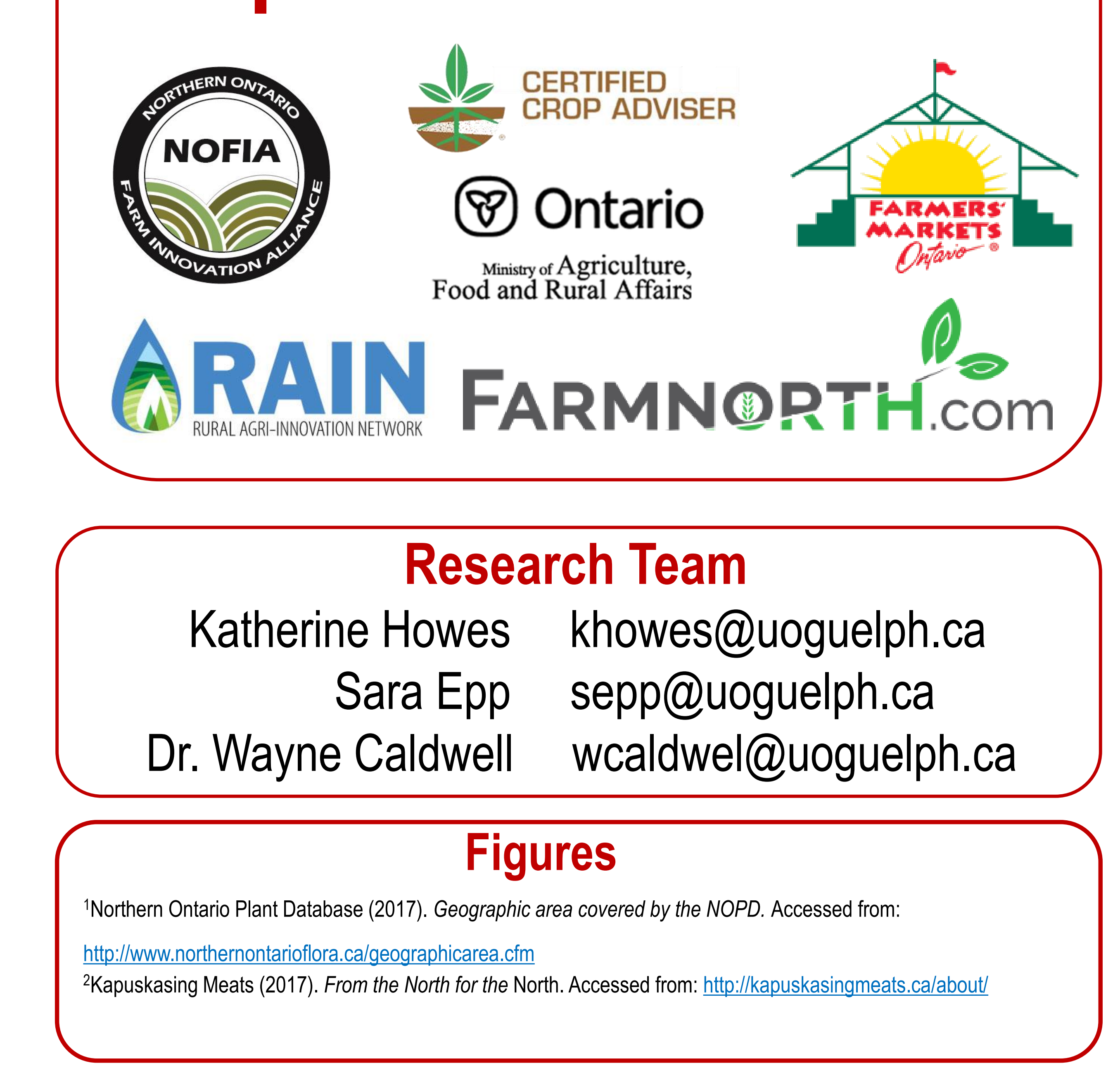

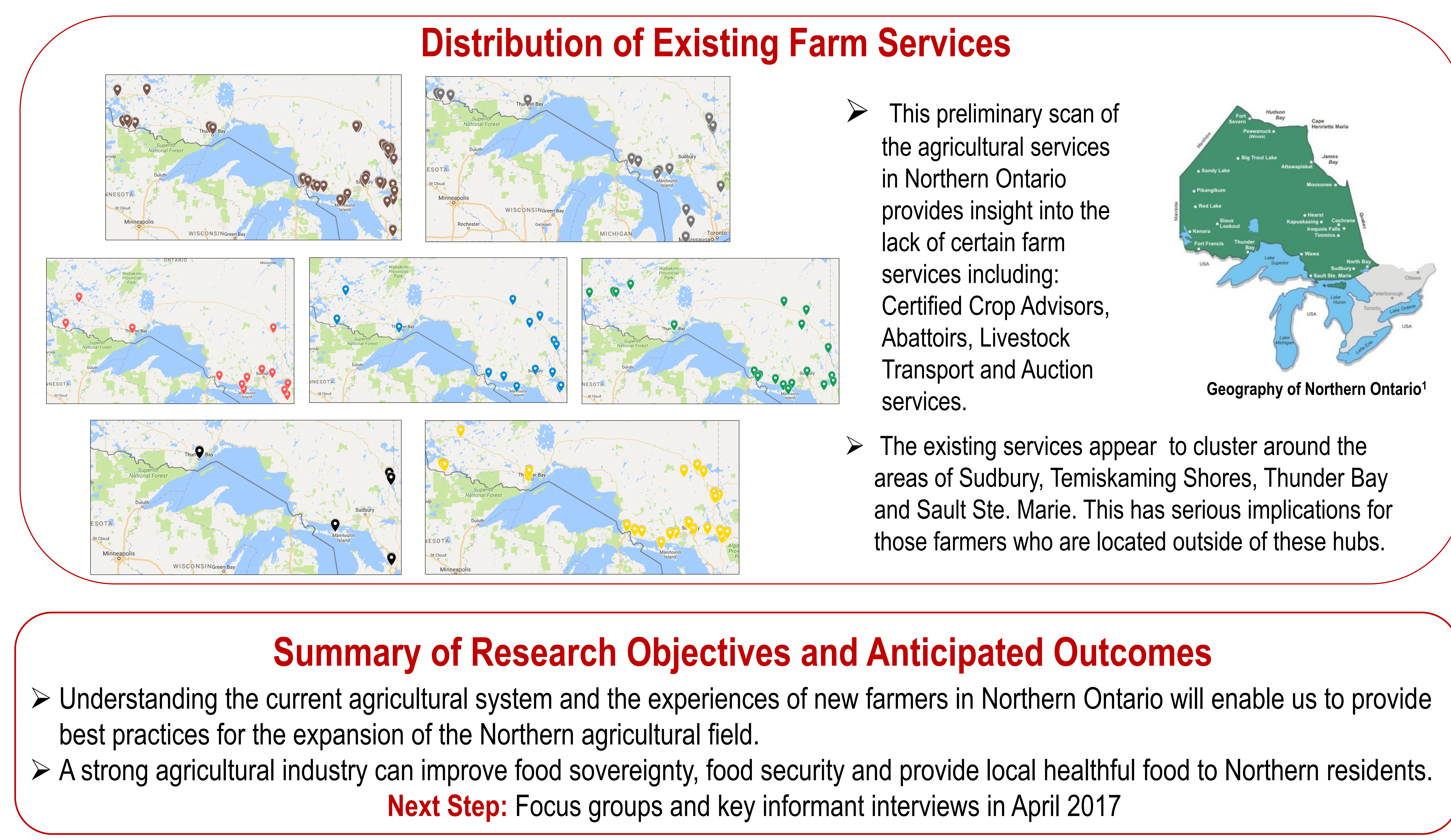

